\title{
Comparison of Multiplex-PCR and Antigen Detection for Differential Diagnosis of Entamoeba histolytica
}

\author{
Helena Lúcia Carneiro Santos ${ }^{1}$, Regina Helena Saramago Peralta ${ }^{1}$, Heloisa Werneck de Macedo ${ }^{1}$, Magali Gonçalves Muniz \\ Barreto $^{2}$ and José Mauro Peralta ${ }^{3}$ \\ ${ }^{1}$ Medical School, Department of Pathology, Fluminense Federal University; Niterói, RJ; ${ }^{2}$ Department of Biology, Oswaldo Cruz Institute; \\ Institute of Microbiology, Federal University of Rio de Janeiro; Rio de Janeiro, RJ, Brazil
}

\begin{abstract}
Amebiasis is an infection caused by Entamoeba histolytica. However, differentiation between $E$. histolytica and Entamoeba dispar, which are morphologically identical species, is essential for treatment decision, precaution of the invasive disease and public health. The purpose of the present study was to evaluate a Multiplex -PCR for detection and differentiation of $E$. histolytica from $E$. dispar from fresh stool samples in comparison with the coproantigen commercial ELISA. Microscopic examination of stools using the Coprotest method, detection of stool antigen by enzyme-linked immunosorbent assay kit and a home made Multiplex-PCR, were used for the diagnosis of amoebiasis infection. Analysis of the 127 stools samples by microscopy examination demonstrated that only $27(21 \%)$ samples were positive for $E$. histolytica/E. dispar complex. Among these stool samples, 11 were positive by Multiplex-PCR, with nine presenting the diagnostic fragment characteristic of $E$. dispar (96 bp) and two presenting diagnostic fragment of $E$. histolytica (132 bp). Among negative samples detected by microscopic examination, three positive samples for $\boldsymbol{E}$. dispar and one positive for $\boldsymbol{E}$. histolytica by Multiplex-PCR was observed. This denotes a low sensibility of microscopic examination when a single stool sample is analyzed. Assay for detection of $E$. histolytica antigen was concordant with multiplex-PCR in relation to $E$. histolytica. Statistical analysis comparing the sensibility tests was not done because of the low number of $E$. histolytica cases. The results demonstrate the importance of the specific techniques use for the differentiation between $E$. histolytica and $E$. dispar.

Key-Words: Multiplex-PCR, Entamoeba histolytica, amebiasis.
\end{abstract}

Amoebiasis is an infection caused by Entamoeba histolytica with or without clinical manifestations [1]. E. histolytica infect approximately $10 \%$ of the world's population, with a higher incidence in tropical and subtropical countries, due to poor sanitary and socioeconomic conditions and nonhygienic practices $[2,3]$.

Individuals infected with $E$. histolytica may show a wide range of clinical manifestations, from asymptomatic colonization to amoebic dysentery and invasive extraintestinal amoebiasis. It has been related that majority of individuals infected are asymptomatic [4-8]. These individuals are reservoir of infection and represent the most neglected category of infected subjects, what might interfere in an epidemiological study and in control of this infectious. Moreover, they should progress to invasive disease $[5,7,9,10]$.

The WHO/Pan American Health Organization/UNESCO Expert Consultation on amoebiasis recognized $E$. dispar as a new specie morphologically indistinguishable from $E$. histolytica and recommended the development of improved methods, using appropriate technologies for specific diagnosis of $E$. histolytica infection in developing countries. The correct identification of this parasite is very important since $E$. histolytica is the only specie within the genus Entamoeba

Received on 5 February 2007; revised 16 May 2007.

Address for correspondence: Dr. José Mauro Peralta. Universidade Federal do Rio de Janeiro. Centro de Ciências da Saúde-IPPMG-Bloco I Cidade Universitária, Ilha do Fundão, Rio de Janeiro/RJ. Zip code: 21.941-590. Phone: 2562-6747 - Fax: 2560-8028. E-mail: peralta@micro.ufrj.br.

The Brazilian Journal of Infectious Diseases 2007;11(3):365-370. (C) 2007 by The Brazilian Journal of Infectious Diseases and Contexto Publishing. All rights reserved. associated with intestinal disease [11]. Identification of other species of Entamoeba is important because they show morphologic similarities between cysts and trophozoites, when diagnostic investigation is done by microscopic examination. In addition, differential diagnosis between $E$. dispar and $E$. histolytica has critical significance for treatment decision, prevention of the invasive disease and health public. Previous studies have related that $E$. dispar can be capable of producing variable focal lesions by erosion of mucosa intestinal in animals $[12,13]$ and of destroying epithelial cells monolayer "in vitro" [14]. Is E. dispar non-pathogenic as its former designation would indicate? E. dispar would be a non-invasive pathogenic. Although, there is no evidence of tissue lesions caused by $E$. dispar in human hosts.

Diagnosis of E. histolytica is usually based on microscopic examination of protozoan morphology. However, it reaches about $60 \%$ sensitivity and can give false-positives due to misidentification of non-pathogenic Entamoeba species [1518]. The examination of fecal samples by optic microscope is not able to identify or differentiate $E$. histolytica from $E$. dispar unless erythrophagocytosis (the presence of ingested RBCs in trophozoites) is seen during microscopic examination $[11,19]$. This feature has been observed among patients with dysentery. Some investigators suggest that this classical feature has long been considered the definitive diagnostic criterion for E. histolytica $[1,6,11,14]$. However, it is rarely observed in chronic amoebic infections.

Methods for antigen detection in stool and polymerase chain reaction (PCR) have been evaluated as diagnostic tools. Antigen detection may be useful as an additional assay to the microscopic diagnosis since this assay detects the galactoseinhibitable adherence protein specifically for E. histoltyica in 
stool. The coproantigen ELISA technique has been suggested to be used in routine diagnosis procedure and epidemiologic studies. However, a comparative study on the use of the ELISA and PCR for detection of E. histolytica indicated that PCR was more sensitive $[6,20]$. In reference laboratories, PCR is the method of choice for differentiation between the pathogenic specie (E. histolytica) from the non-pathogenic (E. dispar). Many investigations have reported successful application of PCR to the diagnosis of amoebiasis as a tool for final confirmatory identification of intestinal amoebiasis [5,6,20-26].

The main purpose of the present study was to evaluate PCR designed for differential detection of E. histolytica and E. dispar from fresh stools samples.

\section{Material and Methods}

\section{Stool Samples}

A total of 127 stool specimens were evaluated using Multiplex-PCR. Specimens from asymptomatic individuals living in two villages in state of Rio de Janeiro (Sumidouro and São Gonçalo) Brazil were obtained. Housing is inadequate in these areas for settlement expansion aside from poor economic condition. This study was reviewed and approved by the Human Investigation Committee of Universidade Federal Fluminense and Fundação Oswaldo Cruz (local ethic committee). Stool sample was taken from individuals who had given their informed consent prior to the collection.

Stool samples from 115 individuals of a rural area in Sumidouro were divided in two aliquots. One aliquot was preserved in formalin, for later microscopic examination, and another was immediately frozen at $-20^{\circ} \mathrm{C}$ for the antigen detection and DNA extraction for PCR analyses. Two stool samples were colleted in different days from 12 individuals living in urban area São Gonçalo and the same procedure as described before was done.

\section{Microscopic Examination of Parasites}

A single fresh stool specimen from each individual was collected in special containers with formalin. Microscopic examination for the presence of parasite (E. histolytcalE. dispar complex cysts and trophozoites) was performed by examination of iodine-stained wet mount after formalin ethyl acetate concentration technique. This test was performed according to the manufacturer's instructions, using a commercial kit, Coprotest [27].

\section{Immunoenzymatic Assay}

Antigen detection was performed on the stool specimens without preservative, using E. histolytica II test kit (Techlab, Inc., Blacksburg, VA), recommended to detect specifically E. histolytica, according to the manufacturer's instructions.

\section{Cultured E. histolytica and E. dispar Trophozoites}

E. histolytica strain HM1:IMSS was grown in TYI-S-33 medium axenically and the E. dispar strain was grown in
Pavlova medium polyxenically. After 48 hours of growth, the culture tubes were placed in ice-cold bath for $5 \mathrm{~min}$ and trophozoites were centrifuged, resuspended in phosphatebuffered saline $\mathrm{pH} 7.2$ and the parasite number was determined. Analytical sensibility of Multiplex-PCR was estimated using cultured trophozoites. Variable amount of trophozoites (200, $100,50,25,15$ and 5) were used to spike a volume of $100 \mathrm{uL}$ stool free of parasite. DNA from the HM1-IMSS strain ( $E$. histolytica) and from E. dispar isolated from stool sample, characterized by isoenzyme analysis, were used as control for all PCR analyses.

\section{Multiplex-PCR \\ Extraction of Nucleic Acids}

DNA from Entamoeba trophozoites and cysts were obtained according to the protocol previously described (Picher et al. 1989) [28] with slight modifications. Approximately $1 \mathrm{~g}$ of unpreserved stool (stored at $-20^{\circ} \mathrm{C}$ ) was homogenized in distilled water and passed through gauze to discard larger detritus. The homogenates were centrifuged at $500 \mathrm{~g}$ per 5 min. The pelllet was resuspended in distilled water and washed three times by centrifugation ( $500 \mathrm{~g}$ for $5 \mathrm{~min}$ ). The sediment was resuspended in $3 \mathrm{~mL}$ of distilled water. The fecal suspension was stored at $-20^{\circ} \mathrm{C}$. For extraction, aliquots $(100 \mu \mathrm{L})$ of fecal suspension was placed in a $1.5 \mathrm{~mL}$ Eppendorff tube, and parasites were lysed with $0.5 \mathrm{~mL}$ of $5 \mathrm{M}$ guanidine isothiocyanate (Promega corporation, USA). The tubes were agitated and incubated at room temperature for $10 \mathrm{~min}$. Lysate materials were cooled on ice for $10 \mathrm{~min}$. After that, $0.25 \mathrm{~mL}$ of cold 7.5 $\mathrm{M}$ ammonium acetate was added. The mixture was kept on ice for $10 \mathrm{~min}$ and then, $0.5 \mathrm{~mL}$ of chloroform/isoamyl alcohol (24:1 v/v) was added. Phases were mixed thoroughly, transferred to a $1.5 \mathrm{~mL}$ Eppendorf tube, centrifuged at 13,800 $\mathrm{g}$ for $10 \mathrm{~min}$ and the sediment suspended with $0.54 \mathrm{~mL}$ of $2-$ propanol. After centrifugation at $3,500 \mathrm{~g}$ for $20 \mathrm{~s}$, the sediment was washed five times with $70 \%$ ethanol by centrifugation (4,000g for $20 \mathrm{~min}$ ) and dried at $37^{\circ} \mathrm{C}$ for $24 \mathrm{hr}$. After that, the dried sample was suspended with $100 \mathrm{uL}$ of TE buffer at $37^{\circ} \mathrm{C}$ for $1 \mathrm{~h}$. This material corresponds to the DNA.

\section{Amplification Reactions}

The Multiplex-PCR was carried out according to a protocol described by Nuñez et al. 2001 [21], with some modifications. Based on the sequences tandemly repeated in the respected extrachromosomal circular DNAs of E. histolytica and E. dispar, a set of oligonucleotide primers specific for $E$. dispar, (EDP1 - 5'ATGGTGAGGTTGTAGCAGAGA3' and EDP2 5'CGATATTG AC CTAGTACT3') and E. histolytica (EHP15'CGATTTTCCCAGTAGAAATTA3' and EHP25'CAAAATGGTCGTCTAGGC3') were prepared. Each primer set was used to specifically amplify a $132 \mathrm{bp}$ fragment from $E$. histolytica (EHP1/EHP2) and a 96 bp fragment from $E$. dispar (EDP1/ EDP2). Multiplex-PCR reaction was performed in a volume of $50 \mu \mathrm{L}$ reaction containing $20 \mathrm{mM}$ of Tris- $\mathrm{HCl} \mathrm{pH}$ 8.4; $50 \mathrm{mM}$ of $\mathrm{KCl} ; 1.5 \mathrm{mM}$ of $\mathrm{MgCl}_{2} ; 40$ pmoles of each 
oligonucleotide primer; $250 \mu \mathrm{M}$ of each deoxynucleoside triphosphate (dNTPs) and 1.25 U of Taq DNA polymerase (Invitrogen Life technologies, USA), $0.1 \%$ of bovine serum albumin (BSA Sigma Chem. Co., USA) e $2 \mu \mathrm{L}$ of DNA sample. PCR was carried out using an GenAmp PCR system 2400 (AB Applied biosystems) thermal cycler and amplification condition were: $3 \mathrm{~min}$ at $94^{\circ} \mathrm{C} ; 30$ cycles of 30 seconds at $94^{\circ} \mathrm{C}$, 30 seconds at $55^{\circ} \mathrm{C}$, and 30 seconds at $72^{\circ} \mathrm{C} ; 5 \mathrm{~min}$ at $72^{\circ} \mathrm{C}$. Amplified products were analyzed by electrophoresis using $2.0 \%$ of agarose gel containing $0.5 \mu \mathrm{g}$ of ethidium bromide/ $\mathrm{mL}$.

\section{Results}

The standardization of Multiplex-PCR was done using DNA from E. histolytica and E. dispar cultured trophozoites. The detection limit was determined by contamination of 100 $\mathrm{uL}$ of stool free of parasite with 200, 100, 50, 25, 15 and five trophozoites or with different concentration of DNA (32 ng to one fg). Multiplex-PCR was capable to detect the specific target DNA sequence when a minimum of five trophozoites or $40 \mathrm{fg}$ of DNA template were used (Figures 1 and 2). Different concentrations of $E$. histolytica DNA ( $16 \mathrm{ng} / \mathrm{mL}, 8 \mathrm{ng} / \mathrm{mL}, 1.6$ $\mathrm{ng} / \mathrm{mL}$ and $0.8 \mathrm{ng} / \mathrm{mL}$ ) were assayed at the same tubes with one fix DNA concentration $(9.2 \mathrm{ng} / \mathrm{mL})$ from $E$. dispar. In this condition, Multiplex-PCR detected both species in all thesamples (Figure 3).

Analysis of the 127 stool samples by microscopy examination demonstrated that $27(21 \%)$ samples were positive for E. histolytica/E. dispar complex. Amongst these stool samples, only 11 were positive by Multiplex-PCR, of which nine presenting the diagnostic fragment characteristic of $E$. dispar (96 bp) and two presenting diagnostic fragment of $E$. histolytica (132 bp) (Table 1). No mixed infection was detected. Among the stool samples in which no E. histolytical $E$. dispar cysts and trophozoites complex were detected by microscopic examination, three were identified as E. dispar and one as E. histolytica when analyzed by MultiplexPCR. The result obtained with coproantigen ELISA test was in agreement with those obtained by the MultiplexPCR (Table 2).

Multiplex-PCR was negative for 15 stool samples that were positive for E. histolytica/E. dispar complex by microscopy examination. In order to clear up this problem, we spiked these samples with $800 \mathrm{pg}$ of DNA template from E. histolytica strains HM1:IMSS. All samples had the E. histolytica DNA fragment amplified showing that the previous negative results are not due to the presence of inhibitors in the sample.

\section{Discussion}

Diagnosis of amoebiasis has been done by traditional microscopic examination of protozoan morphology since amoeba trophozoites description in stool by a physician, Fedor Lösh in 1875. The recent recognition of $E$. dispar as a new non-pathogenic specie, which is morphologically indistinguishable from E. histolytica, has indicated the need
Figure 1. Agarose gel of Multiplex-PCR products amplified by E. histolytca primers EHP1/EHP2 and E. dispar primers EDP1/EDP2. DNA was extracted from stool containing a predetermined number of trophozoites stain HM1-IMSS (see Materials and Methods). E. dispar positive control (lane 1), E. histolytica positive control (lane 2), negative control (lane 3), E. histolytica and E. dispar control (lane 4), stool containing 50 trophozoites (lane 5), stool containing 25 trophozoites (lane 6), stool containing 15 trophozoites (lane 7), stool containing 5 trophozoites (lane 8). 100-pb, molecular size ladder marker (M). The arrow head indicates the position and size of marker.

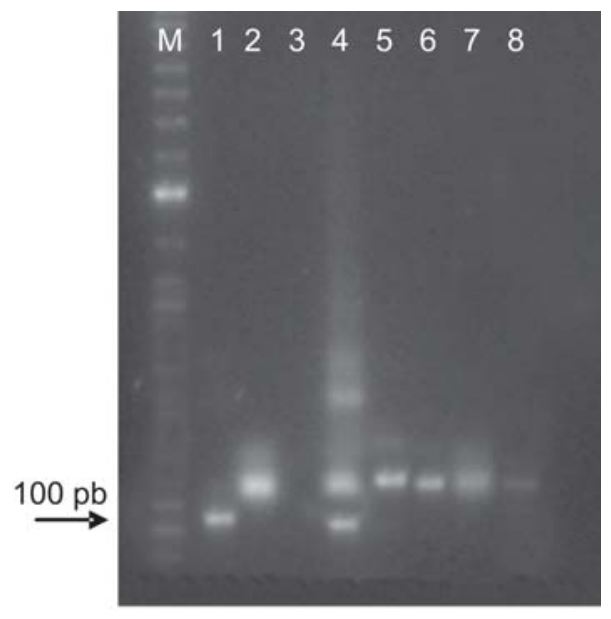

Figure 2. Limit detection of Multiplex-PCR in detection of DNA sample from reference stain (see Materials and Methods). E.histolytica positive control (lane 1), E. dispar positive control (lane 2), negative control (lane 3), E. histoltyica and E. dispar control (lane 4), 2 ng DNA (lane 5), 400 fg DNA (lane 6), 80 fg DNA (lane 7), 40 fg DNA (lane 8), 4 fg DNA (lane 9), 4 fg DNA (lane10), E. histoltyica and E. dispar control (lane 11). 100-pb, molecular size ladder marker (M). The arrow head indicates the position and size of marker.

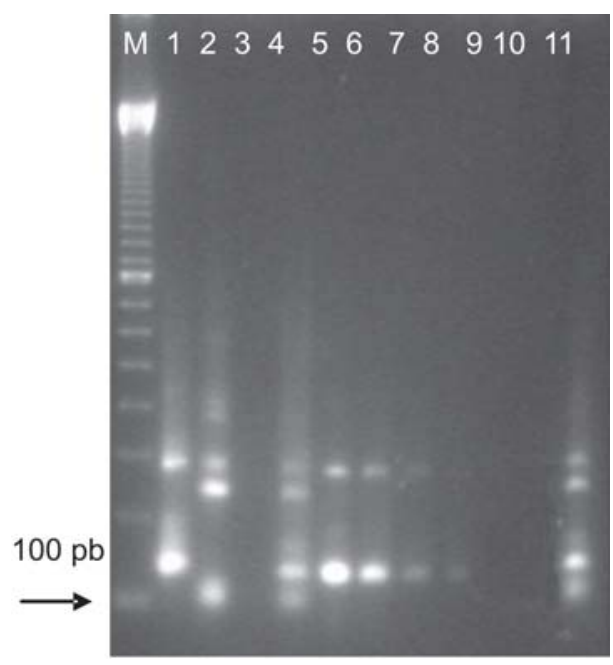


Figure 3. Agarose gel of Multiplex-PCR products amplified by $E$. histolytca primers (EHP1/EHP2) and E. dispar primers (EDP1/EDP2). Multiplex PCR mixtures containing different amounts of DNA from E.histolytica and E. dispar (lane 3-7). 100-pb, molecular size ladder marker (M),E. dispar positive control (lane 1), E.histolytica positive control (lane 2), PCR products from a mixture of $8.0 \mathrm{ng} / \mathrm{mL} \mathrm{DNA}$ from E.histolytca and $9.2 \mathrm{ng} / \mathrm{mL} E$. dispar (lane 3) $1.6 \mathrm{ng} / \mathrm{mL}$ DNA from E.histolytca and $9.2 \mathrm{ng} / \mathrm{mL}$ from $E$. dispar (lane 4), $0.8 \mathrm{ng} / \mathrm{mL}$ DNA from E.histolytca and $9.2 \mathrm{ng} / \mathrm{mL}$ from $E$. dispar (lane 5), $16 \mathrm{ng} / \mathrm{mL}$ DNA from E.histolytca and $9.2 \mathrm{ng} / \mathrm{mL}$ from $E$. dispar(lane 6).

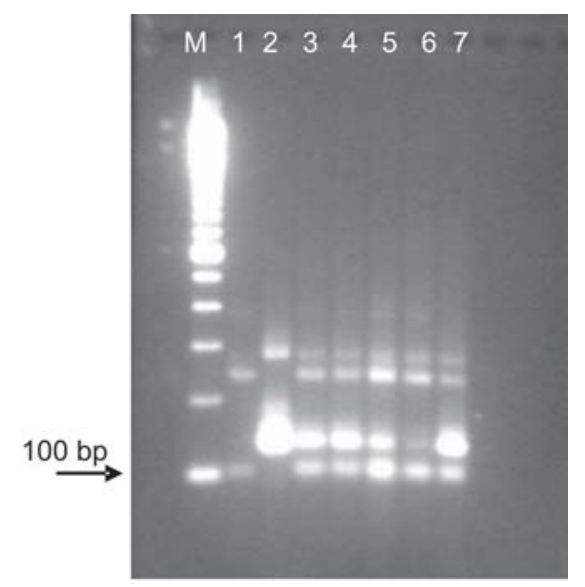

of alternative methods able to differentiate these two species, as recommended by WHO [1]. Petri et al. (2000) reported that microscopic examination of stool should not be used to diagnosis amoebiasis since it is a method with low sensibility, specificity and present false positive results [18]. Dysentery due to entities such as bacteria, virus and other agents should be considered $[3,5,7,10,29]$ and probably may be misdiagnosed as amoebic colitis if microscopy is the sole method used.

Culture of stool samples following isoenzyme analysis has been considered as the gold standard for E. histolytica definitive diagnosis, although it is known to be far from $100 \%$ sensitive [16,31]. This method takes one or more weeks to carry out, is laborious and not practical for routine diagnosis laboratories. Antibodies detection is useful as additional test to confirm the diagnosis of invasive extraintestinal amoebiasis, but not for intestinal form of the disease. It is unable to differentiate acute infection from past infection since antibodies can persist for years after clinical cure [11,16,28].

At the present time, only one commercial test (Techlab $E$. histolytica) can be used to identify E. histolytica protein in the stool sample. Several PCR assays designed to differentiate $E$. histolytica for $E$. dispar have been described [5,6,21,2225,32,33]. Most of them targeted either the small subunit ribosomal RNA gene or specific episomal repeats species. The sensibility and specificity of PCR methods for diagnosis of E. histolytica are very similar to stool culture followed by isoenzyme analysis. However, PCR amplification for detection of small subunit ribosomal RNA genes is almost 100 times more sensitive than currently available ELISA kit for detection of $E$. histolytica antigens, when parasite forms isolated from cultured stool were used [20,24,34]. Recently studies showed that PCR with culture and antigen detection methods from stool samples have the same performance [35].

The primary advantage of using PCR is the possibility of differentiation between $E$. histolytica and $E$. dispar in area where the presence of other Entamoeba species is common. PCR is more accurate to understand the epidemiology of $E$. histolytica and E. dispar infection, contrary to the TechLab E. histoltyica II test, because it is allowed to distinguish the two Entamoeba species. Besides, coproantigen kit detection contains specific antibodies for E. histolytica that recognize antigens on the surface of the trophozoites only, which are generally identified in diarrhea, and not in the cystic stage of the parasite.

In the present study, the data with cultured trophozoites of E. histolytica clearly indicate that PCR technique is sensible and reliable for species differentiation and can be applied for diagnosis in clinical samples. Then, when PCR was used in stool samples from individuals living in two villages of Rio de Janeiro state, Brazil, discrepancy between microscopy and Multiplex-PCR was found. The probability of false negative results by PCR inhibition by fecal constituents is known to be a serious problem. In all PCR negative samples, inhibition factors were checked by spiking these samples with $800 \mathrm{ng}$ of DNA obtained from $E$. histolytica culture forms. No evidence of inhibition was found in any of the Multiplex-PCR negative samples. This result suggested that other species of Entamoeba are presentin this area.

Similar discrepancy has been reported by Pinheiro et al., 2004, [22] when they analyzed 59 cultured stool samples, where 31 samples had Entamoeba trophozoites, but only 23 samples were identified as E. dispar and eight samples were negative for both species. Other study, conducted in Ethiopia with 108 stool samples, demonstrated that only one sample was $E$. histolytica and 77 E. dispar when PCR was used. The remaining 30 samples were negative for both species [19].

High prevalence of $E$. dispar has been described in different countries $[19,22,25,32,36]$. Several studies that have investigated the prevalence of E. histolytica and E. dispar have not considered the presence of other species such as $E$. hartmanni and E. moshkovskii $[19,22,23,36]$. These species were reported in areas of Ghana, Pondicherry and Bangladesh [37-39]. These results suggest that species of Entamoeba that not belong to E. histolytica/E. dispar complex may not be identified. A differential characterization of E. histolytica from other intestinal protozoa is essential because only $E$. histolytica infection requires a specific drug treatment. The discriminate used of such drug can induce development of resistance.

Multiplex-PCR is a robust procedure and easily adapted to routine use in the context of well equipped laboratories and can serve as a tool for the confirmation of microscopy results. 
Table 1. Results of Multiplex-PCR and microscopic examination analysis using stool specimens

\begin{tabular}{lcccc}
\hline \multirow{2}{*}{ Microscopy Examination } & \multicolumn{4}{c}{ Multiplex-PCR } \\
\cline { 2 - 5 } & E. histolytica & $\boldsymbol{E}$. dispar & Negative & Total \\
\hline E. histolytica/E.dispar complex & 02 & 09 & 16 & 27 \\
Other parasites & 01 & 03 & 34 & 38 \\
Negative & 00 & 02 & 60 & 62 \\
Total & 03 & 14 & 110 & 127 \\
\hline
\end{tabular}

Table 2. Results of Multiplex-PCR and antigen detection analysis using stool specimen

\begin{tabular}{lcccc}
\hline & Microscopy Examination & ELISA & & \multicolumn{2}{c}{ Multiplex-PCR } \\
\cline { 3 - 5 } & & & E. histolytica & E. dispar \\
\cline { 3 - 5 } & 27 & $03 *$ & $03^{*}$ & 09 \\
Positive & 100 & 83 & 124 & 118 \\
Negative & 127 & 86 & 127 & 127 \\
\hline
\end{tabular}

* Same positive specimens.

However, PCR techniques do not substitute the direct microscopy stool examination, which widely screen for virtually intestinal parasite, but could be a useful tool for diagnosis and epidemiological studies in areas where E. histolytica is endemic.

\section{Acknowledgements}

We thank Dr. Lúcia Feitosa de Menezes from Universidade Federal do Rio de Janeiro, Brazil for providing us with cultures of E. histolyca strains HM1:IMSS.

This work was supported by CNPq and FAPERJ.

\section{References}

1. World Health Organization. Amoebiasis. Report on the WHO/ Pan American Health Organization/ UNESCO Expert Consultation, Mexico City. Geneva- WHO. W Epidemiol Rec 1997; 72:97-100.

2. Rivera W., Tachibana H., Kanbara H. Field study on the distribution of Entamoeba histolytica and Entamoeba dispar in the Northern Philippines as detected by the polimerase chain reaction. Am J Trop Med Hyg 1998;59:916 -21.

3. Ramos F., Valdez E., Morán P., et al. Prevalence of Entamoeba histolytica and Entamoeba dispar in a Highly Endemic Rural Population. Arch Med Res 2000;31:S34-5.

4. Walsh J.A. Problems in recognition and diagnosis of amebiasis: estimation of the global magnitude of morbidity and mortality. Rev infect Dis 1986;8:228-38.

5. Evangelopoulos A., Spanakos G., Patsoula E., Vakalis N. A nested multiplex PCR assay for the simultaneous detection and differentiation of Entamoeba histolytica and Entamoeba dispar in faeces. Ann Trop Med Parasitol 2000;94:233-40.

6. Gonin P., Trudel L. Detection and Differentiation of Entamoeba histolytica and Entamoeba dispar isolates in clinical samples by PCR and Enzyme-Linked Immunosorbent Assay. J Clin Microbiol 2003;41:237-41.

7. Stanley S. L. Amoebiasis. Lancet 2003;361:1025-34.

8. Huston C. D. Parasite and host contributions to the pathogenesis of amebic colitis. Trends Parasitol 2004;20:23-6.

9. Haque R., Huston C. D., Hughes M., et al. Current concepts: Amebiasis. N Engl J Med 2003;348:1565-73.

10. Blessmann J., Van L. P., Nu P.A.T., et al. Epidemiology of amebiais in a region of high incidence of amebic liver abscess in Central Vietnam. Am J Trop Med Hyg 2002;66:578-83.
11. Tanyuksel M., Petri W.A.P. Laboratory Diagnosis of Amebiasis. Clin Microbiol Rev 2003;16:713-29.

12. Chadee K., Smith J.M., Meerovitch E. Entamoeba histolytica: electrophoretic isoenzyme parttners of stains and their virulence in the cecum of gerbilis (Meriones unguiculatus). Am J. Trop Med Hyg 1985;34:870-8.

13. Vohra H., Bhatti N.K., Ganguly N.K., Marajan R.C. Virulence of pathogenic and non-pathogenic zymodemes of Entamoeba histolytica (Indian strains) in guinea pigs. Trans R Soc trop Med Hyg 1989;83:648-50.

14. Espinosa-Cantellano M. ,Gonzalez-Robles A., Chavez B., et al. Entamoeba dispar: ultrastructure, surface properties and cytopathic effect. J Euk Microbiol 1998;45:265-72.

15. Gonzalez-Ruiz A., Haque R., Aquire A., et al. Value of microscopy in the diagnosis of dysentery associated with invasive Entamoeba histolytica. J Clin Pathol 1994;47:236-9.

16. Haque R., Petri W.A. Diagnosis of Amebiasis in Bangladesh. Arch Med Res 2006;37:273-6.

17. Urdaneta H., Rangel A., Martins M.S., et al. Entamoeba histolytica: Fecal antigen capture immunoassay for the diagnosis of enteric amebiasis by a monoclonal antibody. Rev Inst Med Trop São Paulo 1996; 38:39-44.

18. Petri W.A., Haque R., Lyerly D., Vines R.R. Estimating the Impact of Amebiasis on Health. Parasitol Today 2000;16:320-1.

19. Kebede A., Verweij J.J., Petros B., Polderman A.M. Misleading Microscopy in Amoebiasis. Trop Med Int Health 2004;9:651-2.

20. Mirelman D., Nuchamowitz Y., Stolarsky T. Comparison of use Enzyme-Linked Immunosorbent Assay-Based Kits and PCR amplification of rRNA genes for simultaneous detection of Entamoeba histolytica and E. dispar. J Clin Microbiol 1997;35(9):2405-7.

21. Nuñez Y.O., Fernández M.A., Torres-Nuñez D., et al. Multiplex polymerase chain reaction amplification and differentiation of Entamoeba histolytica and Entamoeba dispar DNA from stool samples. Am J Trop Med Hyg 2001;64:293-7.

22. Pinheiro S.M., Carneiro R.M., Aca I.S., et al. Determination of the prevalence of Entamoeba histolytica and E. dispar in the Pernambuco state of northeastern Brazil by a polymerase chain reaction. Am J Trop Med Hyg 2004; 70:221-4.

23. Verweij J.J., Blotkamp J., Brienen E.A.T., et al. Differentiation of Entamoeba histolytica and Entamoeba dispar cysts using polimerase chain reaction on DNA isolated from faeces with spin columns. Eur J Microbiol Infect Dis 2000;19:358-61.

24. Freitas M.A.R., Vianna E.N., Martins A.S., et al. A Single step duplex PCR to distinguish Entamoeba histolytica from Entamoeba díspar. Parasitology 2004;128:625-8. 
25. Rivera W.L., Tachibana H., Kanbara H. Application of the Polymerase Chain Reaction (PCR) in the epidemiology of Entamoeba histolytica and Entamoeba dispar. Tokai J Exp Clin Med 1999;23:413-5.

26. Qvarnstrom Y., James C., Xayavong M., et al. Comparison of Real-Time PCR Protocolos for Differential diagnosis laboratory diagnosis of Amebiasis. J Clin Microbiol 2005;43:5491-7.

27. Serqueira F.L. Coprotest: metodologia confiável para o exame parasitológico de fezes. Laes \& Laes 1988;9:5-2.

28. Pitcher D.G., Saunders N.A., Owen R.J. Rapid extraction of bacterial genomic DNA with guanidine thiocyanate. Lett Appl Microbiol 1989; 4: 1513-21.

29. Petri A.W., Singh U. Diagnosis and Management of Amebiasis. Clin Infec Dis 1999;29:1117-25.

30. Sehgall R.M., Abd-Alla A.H., Moody P.L., Ackers J. Comparison of two media for the isolation and short-term culture of Entamoeba histolytica. Trans R Soc Trop Med Hyg 1995;89:394.

31. Ackers J.P. The diagnostic implications of the separation of Entamoeba histolytica and Entamoeba dispar. J. Biosci 2002;27:573-8.

32. Acuna-Soto R.J., Samuelson P.D., Girolami L., et al. Application of the polymerase chain reaction to the epidemiology of pathogenic and nonpathogenic Entamoeba histolytica. Am J Trop Med Hyg 1993;48:58-70.
33. Novati S., Sironi S.M., Granata S., et al. Direct sequencing of the PCR amplified SSU rRNA gene of Entamoeba dispar and the design pf primers for rapid differentiation from Entamoeba histolytica. Parasitology 1996;112:363-9.

34. Troll H., Marti H., Weiss N. Simple differential detection of Entamoeba histolytica and Entamoeba dispar in fresh stool specimens by sodium acetate-acetic acid-formalin concentration and PCR. J Clin Microbiol 1997;35:1701-5.

35. Haque R., Ali I.K., Akther S., Petri W.A. Comparison of PCR, isoenzyme analysis, and antigen detection for diagnosis of Entamoeba histolytica infection. J Clin Microbiol 1998; $36: 449-52$.

36. Heckendorn F., Goran E.K.N., Ferger I., et al. Species-specific field testing of Entamoeba spp. in area of high endemicity. Trans R Soc Trop Med Hyg 2002;96:521-8.

37. Ali I.B., Hossain M.B., Roy S., et al. Entamoeba moshkovski Infections in Children in Bangladesh. Emerg Infec Dis 2003; $9: 580-4$

38. Parija S.C., Khairnar K. Entamoeba moshkovskii and E. dispar associated Infections in Pondicherry, India. J Health Popul Nutr 2005;23:292-5.

39. Verweij J.J., Oostvogel F., Brienen E.A., et al. Prevalence of Entamoeba histolytica and Entamoeba dispar in Northern Ghana. Trop Med Int Health 2003;8:1153-6. 